\title{
DOS CRIMES CONTRA A ECONOMIA POPULAR
}

\section{Edgard Magalhães Noronha}

\author{
Subprocurador Geral da Justiça de São Paulo
}

Já de há muito, afirmaram os sociólogos do direito penal que toda civilização tem o seu crime. É isso bem compreensível, porque sabemos que a evolução social não se faz de maneira contínua, sofrendo, através dos tempos, retrocessos na sua trajetória ascencional. Parte integrante dêles são os novos crimes, pois o progresso, proporcionando condições de vida diferentes e rasgando horizontes ignotos, cria a oportunidade e o ambiente para que surjam.

E exato que delitos conhecidos desde os alvores da humanidade continuam ainda a afligí-la. Já não falamos no homicídio, mas em outros que, em ronda sinistra, cercam e acompanham a criatura humana. Nas velhas leis, como o Código de Hamurabbi, o de Manú, o Gênesis, o Êxodo, o Deuteronômio, o Levítico e outras, vamos encontrar, p. ex., a cominação da pena ao furto. O roubo assume suas características legislativas próprias de crimen vis na Lex Cornelia de Sicariis. O dano foi conhecido das XII Tábuas e da Lex Aquilia. E, assim, vêm os crimes resistindo ao progresso e à civilização. Não há dúvida que alguns desapareceram. Em nosso Código mesmo, deparamos figuras delituosas que não têm expressão entre outros povos, como, v.g., a alteração de limites, prevista no art. 161. Punida pela legislação hebraica, no Deuteronômio, com o anátema "Maldito aquêle que arrancar o têrmo do seu próximo" (XXVII, 17), dificilmente poderá, hoje, ser praticada em países de pequena 
superfície e onde a propriedade se encontre inteiramente consolidada.

Extingue a civilização certos crimes, mas infelizmente não impede outros e até enseja alguns. De modo geral, podemos dizer que impele o homem aos delitos que não se caracterizam tanto pela violência ou o sangue, mas para os do enliço e da fraude. Nos dias que vivemos, esta reina nos domínios do crime. Surge mesmo até onde outrora predominava a brutalidade. $\mathrm{O}$ assassino moderno prefere a astúcia do criminoso d" "O Inocente", de Dannunzio, expondo o recém-nascido ao frio de uma noite de Natal, para fazê-lo morrer de pneumonia, à sanha de Raskolnicoff do "Crime e Castigo" de Dostoiewsky, sacrificando a golpes de machado as duas anciãs. Oferece a fraude maiores garantias ao delinquente e não repugna tanto aos seus sentimentos de homem civilizado, se assim se pode dizer. Facilita-lhe também a emprêsa. Já dizia o grande florentino:

"Ecco la fiera con la coda aguzza, che passa' monti e rompe i muri e l'armi, ecco colei che tutto il mondo appuzza!"

E como forma de criminalidade evolutiva, ela não se acomoda apenas nas baixas camadas sociais, porque penetra também outras esferas. Domina nos grandes centros financeiros e desce um pouco para se apresentar em meios de menor altitude, porém, de maior extensão. Toma formas diversas, veste-se com roupagens variadas, obedecendo ao gôsto de quem as usa. Com habilidade, procura-se, hoje, confundir o comércio e a indústria com a exploração do próximo. Não basta a especulação lícita, mister se faz a ilícita, cuidando-se que lindes não as separem. Certo é que como não existe um critério seguro e constante para distinguir o lícito do ilícito, senão o do direito positivo, há sempre bôa margem para que inescrupulosos indivíduos, evitando os escolhos da lei ou mascarando sua atividade, procurem dar aspecto honesto às burlas ou aos expedientes enganosos.

Mas a consciência popular veio paulatinamente despertando contra as ciladas torpes ou fraudulentas. Não se confunde mais atividade bancária ou mutuária com agiotagem. Todos sabemos o que seja açambarcamento, isto é, a aquisição da totali- 
dade de produtos em determinada praça, destinada a anular a concorrência, para o fim da imposição do preço. As coalisões capitalistas, a asfixia econômica, a alteração injustificável de preços, o lucro onzenário, o enriquecimento ilícito com dano de inúmeras pessoas, as cláuisulas abusivas nos contratos de compra e venda a prestações, a concorrência desleal, a gestão fraudulenta ou temerária de sociedades de economia coletiva, etc., tudo isso não mais passa despercebido.

Alguns dêsses fatos não constituem mesmo novidades. A respeito da agiotagem, p. ex., já dispunham as vetustas Ordenações do rei Felipe. Aliás, a incriminação vinha de longe, como se vê do Êxodo, do Deuteronômio e das XII Tábuas (transgressão do fenus unciarum).

Todavia, a capitulação como crimes da maior parte dessas práticas não remonta a longínquas éras, e, quanto a nós, a ação preventiva e repressiva do Estado, através da lei, foi só nas duas últimas dezenas de anos que se fez sentir de modo mais seguro e eficaz. Compreendeu-se, então, diante do que se passava e pela natural marcha das cousas, que o liberalismo econômico, que vinha reinando era, na verdade, o arbítrio da vontade dos fortes e afortunados sôbre a impotência dos fracos e desfavorecidos. Daí a intervenção do Govêrno, porfiando acomodar os interêsses particulares com o bem coletivo.

Não se aplaude o esmagamento do indivíduo pelo Estado. Seria a substituição de um mal por outro. Não se dispensa, porém, sua ação, procurando empeçar os que furtam com unhas maliciosas, como nos lembra o Pe. Vieira nêste quadro sugestivo: "Por taes tenho os que escondem e reprezão o pão, para que não se veja abundancia e appareça a carestia e suba o preço. $\mathrm{O}$ mesmo fazem os mercadores com sedas e pannos: mostrão-vos só huma pessa da côr, ou lote, que buscais e jurão-vos por esta alma, ponde a mão nos botoens da roupeta, que não ha em toda a rua Nova mais que este retalho, e assim vo-lo talhão pelo preço que querem; e em gastando aquelle, apparece logo outro, e outro cento delles: como o ramo de Sibylla de Eneas, que quanto mais nelle cortavão, tanto mais renascia, cada vez mais formoso. Mas que muito que fação isto na rua Nova, quando até os que não professão a ley velha, fazem o mesmo nas carnes, vinhos e azeites, que vem vender a Lisboa: vem 
trazendo tudo aos poucos, porque se o trazem junto, ha abundancia e em a havendo abatem os preços: e para que subão e enchão bem as bolças com a assolação do povo, ajudão-se na malicia, que está descoberta, e será remediada, se se der por perdida toda a fazenda, que andar retida, e atraveçada com semelhantes estanques".

As sociedades atuais não mais toleram êsse estado de cousas, essa luta desigual, sentida e apontada, como vemos, desde priscas eras, mas nem sempre punida. Intervem o Govêrno, no justo anceio, senão de minorar a desigualdade econômica, de proibir a exploração do homem pelo homem, eliminando os desmandos e abusos, reprimindo a fraude, dando caça aos "profiteurs" do povo, ajustando a concorrência, atenuando os efeitos da plus-valia, para que a disparidade entre o preço da mercadoria-trabalho e o de seu produto não atinja a culminâncias. Tudo isso sem que tal ação imponha hipertrofia do Estado, com aniquilamento do indivíduo. Não se mata a iniciativa privada, mas impede-se que ultrapasse o justo limite do lucro à custa da ruina do povo.

Em defesa da economia coletiva, tivemos, então, grande número de decretos-leis, cada qual tendo escopo determinado, embora todos se enquadrassem na finalidade única do bem coletivo. Bem sei que não foram êles completos. Outros deveriam ter surgido. Imperfeita foi sua execução, não se alcançando de pronto os resultados a que se visava. Deficiências naturais do novo organismo, destinado a aplicá-los, falta de jurisprudência, que não contava ainda tempo para se firmar.

Extinta a Justiça Especial, destinada a julgar os delitos contra a economia popular, passou a árdua missão para a Justiça comum. Essa mesma Justiça que, com sacrifício de seus membros, vem servindo com fé, honestidade e devoção ao Brasil.

$\mathrm{Na}$ luta em que ela se empenha, de pé e vigil como sempre o Ministério Público. Magistratura militante, como disse Scarlata, ou instituição destinada a ligar a ordem administrativa à judiciária, como ensinava o Marquês de S. Vicente - pois que não me preocupa neste momento discutir sua essência, e antes apontar sua finalidade - cabe-lhe papel de relêvo no combate ao crime. É o órgão da lei e fiscal da sua execução, como fre- 
quentemente se afirma. E nêsse mister, ampla é sua atividade e múltiplos os deveres. Como árvore frondosa, seus ramos altaneiros tocam os mais elevados da árvore da magistratura. Sua ação, na defesa da sociedade, só conhece limites onde cessa também a do Poder Judiciário: perante a Suprema Côrte do País luta e se empenha pela exata aplicação da lei.

Grande responsabilidade lhe incumbe, dessarte, na formação da jurisprudência dos Tribunais. $\mathrm{E}$ nêste particular, quero pôr em realce o julgado do E. Tribunal do Estado de São Paulo, a cujo saber jurídico sempre me curvei respeitosamente, embora me reservando o direito inalienável de, uma vez ou outra, dissentir. $\mathrm{Na}$ verdade, anima-me sòmente o desejo de ver esclarecida definitivamente questão que julgo de interêsse, em matéria de crimes contra a economia popular, pois se trata de exegese que abrange várias leis a ela referentes e que, a meu ver, não condiz com os interêsses da sociedade. Foi proferida pelas Câmaras Criminais Conjuntas de S. Paulo. Não houve voto discrepante. Julgava-se pedido de habeas-corpus, que foi concedido, anulando-se o processado.

Esclarecidas estas circunstâncias, estais já sentindo o arrojo e a audácia de quem se propõe discutir Aresto de semelhante porte. São mestres do direito penal que o proferiram, luzeiros da cultura jurídico-penal paulista, que diàriamente, com prodigalidade, nos ministram ensinamentos da ciência de Carrara.

Entretanto, estou que o M. Público não se pode quedar quando veja periclitarem os interêsses da sociedade. Não me insurjo contra a decisão proferida no caso. Ela apreciou bem a espécie, anulando sentença, em si contraditória. Não digo que constitua jurisprudência constante e uniforme. Mas o que, então, se afirmou, por mais de uma vez vem sendo repetido no pretório paulista, pelos advogados, em sua nobre missão de defender seus constituintes, parecendo-me conveniente que peça a atenção dos meus colegas.

Encontra-se o venerando Aresto na Rev. dos Trs., vol. 181, pg. 66. Disseram as Colendas Câmaras: "Além de desprezar a classificação exata, ainda aplicou pena já inexistente, em sua quantidade e qualidade. Segundo o art. $1 .^{\circ}$ do Dec. Lei n. ${ }^{0} 9.914$, 
de 17 de setembro de 1946, todos - reparai bem: todos - os delitos contra a economia popular, previstos na legislação anterior ao decreto-lei 9.840 de 11 de setembro de 1946, ficaram incorporados e sujeitos às alterações dêste decreto. As penas anteriormente cominadas foram reduzidas, de maneira unifor$m e$, às de um a seis mêses de detenção e multa de um a cinquenta mil cruzeiros, nos termos do art. $2 .^{\circ}$ do decreto de consolidação. Vedada, portanto, se achava a aplicação da pena mínima de seis mêses de prisão celular, com base no decreto-lei n..$^{\circ} 869$, revogado nêsse ponto, quando o mínimo a ser aplicado deveria ser outro, de acôrdo com a disposição vigente do decreto-lei n. ${ }^{\circ} 9.840 "$.

Afirmou-se, portanto, que todos os crimes contra a economia popular capitulados nas leis anteriores ao decreto-lei $n .^{\circ}$ 9.840 de 11 de setembro de 1946 tiveram suas penas uniformizadas, entre os extremos de um a seis mêses de detenção, ex-vi do art. $1 .^{\circ}$ do dec. lei n. 9.914 de 17 de setembro de 1946. Dentre os decretos-leis anteriores, por sua importância, destacam-se o de n. ${ }^{0} 869$ de 18 de novembro de 1938, o 22.626 de 7 de abril de 1933, o 4.598 de 20 de agôsto de 1942 , o 9.669 de 29 de agôsto de 1946 e muitos outros que longo seria citar. Basta, porém, para dar realce à matéria a invocação do Dec-Lei 869 .

Cotejando-se as leis aludidas pela respeitável decisão, o que noto é que o de $n .^{\circ} 9.840$, de 11 de setembro de 1946 , quiz consolidar os delitos contra a economia popular e dêsse modo dispôs que seriam êles os capitulados pelos decretos 869 de 18 de novembro de 1938 e 9.669 de 29 de agôsto de 1946. Isso estabeleceu textualmente no art. $1 .^{\circ}$, dizendo: "Os delitos e as penas contra a economia popular, sua guarda e seu emprêgo são os definidos nos decretos-leis 869 de 18 de novembro de 1938 e 9.669 de 29 de agôsto de 1946, com as alterações dêste decreto-lei".

Contudo, para logo se notou a grave omissão da lei, mencionando nêsse dispositivo sómente aquêles decretos, donde veio, então, o de n. ${ }^{\circ} 9.914$, de 17 de setembro de 1949, para declarar que outros crimes capitulados em vários decretos estavam também compreendidos naquêle, soando o artigo inicial dessa lei: "Os delitos contra a economia popular, por equiparação, previstos na legislação anterior ao Dec. Lei 9.840 de 11 de 
setembro de 1946 não se consideram excluidos da definição contida em seu art. 1. ". Com efeito, era necessário que assim se fizesse porque várias leis, como os decretos 1.041, 2.524, 22.626, 9.125, etc., não haviam sido citadas no art. $10^{\circ}$ do Dec. Lei 9.840 . Acresce que, como é sabido, o próprio Dec. Lei 869 havia sido modificado por alguns diplomas.

Dir-se-á, porém, que aquêle artigo usou os dizeres "com as alterações dêste decreto-lei", e como êle se refere à pena de detenção de um a seis mêses, esta é que é a cominada para todos os delitos contra a economia popular, como asseverou o respeitável Acórdão das Câmaras Criminais Conjuntas de S. Paulo.

Nada há, porém, que possa levar a êsse juizo. A pena máxima de seis mêses de privação de liberdade é cominada para os delitos definidos no art. $2 .^{\circ}$. Ora, a análise dêsse artigo mostra que êle reproduziu e modificou figuras delituosas preexistentes, ao mesmo tempo que definia outras. A êsses delitos contidos no art. $2 .^{\circ}$, e tão só a êsses, é que aplicou a pena de um a seis mêses de detenção.

Com efeito, analisando-se êsse dispositivo, vemos que os incisos I e II reproduzem textualmente o art. 11 b) e c) do Dec. Lei 9.125 de 4 de abril de 1946.0 n. ${ }^{\circ}$ III repete ipsis litteris a alínea d) e o art. 10 do mesmo decreto-lei. Os incisos IV e IX completaram disposições das várias leis do inquilinato. Os de n. ${ }^{\circ} \mathrm{s}$ VI e VII referem-se expressamente a disposições do Dec. Lei 9.669 de 29 de agôsto de 1946. E o VIII não se afasta, em sua substância, do disposto no art. $2 .^{\circ} \mathrm{n} .0^{\circ} \mathrm{V}$ do Dec. Lei 869 e de outros que versaram a matéria.

Em meu fraco entender, penso que o Dec. Lei 9.840 só cominou a pena mencionada em seu artigo $20^{\circ}$ - um a seis mêses de detenção - aos delitos que aí perfilou. Dêsse modo, quando em seu artigo $10^{\circ}$ diz que são crimes contra a economia popular os definidos em leis anteriores, com as modificações que impõe, só se pode referir às alterações expressas no art. $2 .^{\circ}$, que não sómente dizem respeito ao conteudo delituoso, mas à pena também. Consequentemente, os delitos definidos nos decretos leis, citados em seu art. $1 .^{\circ}$, só têm a pena aludida, quando invocados no art. $2 .^{\circ}$.

Se assim não fôsse, por que iriam os incisos VI e VII dêsse artigo referir-se aos de $n .{ }^{\circ} \mathrm{s}$ II, III e V do art. 18 e ao art. 21 
do Dec. Lei 9. 669, para dizerem que seriam apenados com um a seis mêses de detenção, se isso já estava subentendido no art. $10^{0}$ ?

A verdade é que essa lei teve em vista reafirmar quais eram os crimes contra a economia popular, em seu art. $1 .^{\circ}$, e no $2 .^{\circ}$ alterar e completar figuras delituosas a que cominou a pena mencionada. Não se pode dar outra interpretação. Desde que um dispositivo penal declare que se devem considerar as modificações que enunciará em outra disposição e se essa capitula crimes definidos em outras leis, estas só são modificadas nos casos aí especificados. Quanto aos crimes dantes previstoss e não considerados na lei posterior, permanecem inalterados. 0 silêncio da lei, nêste particular, não pode ser tomado senão no sentido da imutabilidade das que as precederam, pois onde a lei quer diz — "Lex, si aliud voluisset, expressisset" -

Dois argumentos cito em abono de meu ponto de vista. Se intenção fôra da lei citada uniformizar tôdas as penas dos crimes contra a economia popular, bastaria um artigo sómente que, invocando todos os decretos já existentes, cominasse a pena desejada, excusando-se de se derramar, na disposição seguinte, em uma casuística de todo injustificável, porque já cornpreendida nos diplomas aí mencionados. Se é princípio de hermenêutica que a lei não contem palavras imutáveis, mui mais procedente será afirmar-se que não admite disposições supérfluas.

Por visar aquêle decreto a uma consolidação de leis é que não se deduz que a pena será única. Consolidação é a reunião de várias leis em uma única, guardando elas as particularidades e característicos próprios. Justifica-se, em regra, quando em falta de um Código, sejam abundantes, dificultando o conhecimento não só dos especialistas, mas do povo e do indivíduo, que não se excusam em declarar a ignorância.

O outro argumento provem da interpretação sistemática, aliás, já feita em parte, pelo confronto da lei em questão com suas similares. Entretanto, examinando-a, encontramos o art. $6 .^{\circ}$ que reza: "O rito processual dos crimes contra a economia popular, definidos nos decreto-leis n. ${ }^{\circ} 869$ de 18 de novembro de $1938,9.669$ de 29 de agôsto de 1946 e nêste decreto lei, obedecerá ao disposto no art. 539 do C. Proc. Penal, ainda mesmo 
que o máximo da pena seja superior a dois anos". Êste dispositivo, como vemos, após mencionar crimes capitulados em outros estatutos e aludir aos que êle definiu, prescreve determinado rito processual, ainda que o máximo da pena ultrapasse a dois anos. Logo, é êle próprio quem diz haver pena superior a seis mêses, é êle mesmo que afirma não as ter uniformizado. Se assim não fôsse, como se explicar essa alusão a pena superior a dois anos? Se a ela se referiu é porque continua a existir. Que dizer de um legislador que se preocupasse com delitos inexistentes e penas já proscritas?

A finalidade do Dec. Lei 9.840 não foi uniformizar penas. Foi indicar as leis vigentes acêrca da economia popular, o que, aliás, fez de modo lacunoso; melhorar e aperfeiçoar algumas definições de crimes já existentes; dispôr medidas complementares e traçar o rito processual. Este foi o objetivo, que é confirmado pelas palavras.

Ora, não me parece que quando a interpretação gramatical se harmoniza com a teleológica, reste ainda alguma cousa para o intérprete investigar. É repetir com Jimenez de Asúa : "Cuando el uso de la interpretación gramatical y teleologica nos conduce al mismo resultado podemos decir que nos hallamos en posesión de la verdad".

Além do mais, é necessário lançarmos nossas vistas para outro ponto. Não são poucos os crimes contra a economia do povo, cuja pena é elevada. É a justa reação do legislador contra os exploradores dos desvalidos. No Dec. Lei 869 de 18 de novembro de 1938, p. ex., vemos nada menos que dez figuras delituosas apenadas com 2 a 10 anos de prisão celular. Qual a razão, que mistério, que imperscrutável propósito levaria o legislador a baixar essas penas para o máximo de seis mêses de detenção?

É necessário atentar que os incisos IX e X do referido Dec. Lei 869 capitulam delitos bastante graves. Um, o de gestão temerária ou fraudulenta de sociedades ou institutos de economia popular; outro, o de falsear escritas, relatórios, pareceres ou quaisquer informações devidas a sociedade civis ou comerciais. São delitos que muito se aproximam dos crimes definidos no artigo 177 do C. Penal, no capítulo referente ao estelionato 
e outras fraudes, cuja pena vai de um a quatro anos de reclusão. Na verdade, o característico que mais os extrema é o peculiar aos crimes contra a economia popular: "dano efetivo ou potencial ao patrimônio de um indefinido número de pessoas". Lá, no estelionato, as vítimas podem ser uns poucos e abonados indivíduos que se constituiram em sociedade. Aqui, é a massa, centenas ou milhares de pessoas que economisando cruzeiro por cruzeiro, empregam essa minguada economia em uma sociedade que não passa de uma "arapuca" para colhê-la e tragá-la. Não é possível que no primeiro caso, a lei punisse com o máximo de quatro anos de reclusão e no segundo levasse sua severidade até ao extremo irrisório de seis mêses de detenção. Seria dizer que o legislador viu nas circunstâncias do maior número de vítimas e em seu desvalimento - pois, a defesa privada é sempre menor nos pobres e simples - circunstância atenuante, razão de aplicar pena sensivelmente mais branda.

Concluo, portanto, sem embargo do respeito e da suma admiração aos Exmos. Snrs. Desembargadores das Câmaras Criminais Conjuntas de meu Estado, a êsses Juizes que, sem favor, podem ser considerados "maestri di color' chi sano", que os Decs. Leis 9.840 e 9.914 de 11 e 17 de setembro de 1946 não uniformizaram as penas dos crimes contra a economia popular, baixando-as aos extremos bem suaves de um a seis mêses de detenção.

Certo, não cuido de assunto de maior tomo, mas creio que terá sua utilidade. Confesso ignorar a jurisprudência dêsse Estado culto e progressista. Se ela se orientou no sentido que aqui apontei, será inestimável elemento para a convicção do meu acerto; se, ao revés, houver também esposado aquela opinião do E. Tribunal de S. Paulo, talvez que em algumas de minhas palavras terei assinalado uma rota a caminheiros mais seguros que a batam e vençam.

Poder-se-ia também lastimar que esteja eu apelando para uma questão que, em suma, se resume na aplicação de pena mais leve ou grave para os delitos contra a economia do povo.

Disso, entretanto, me defenderei, porque penso que em matéria de direito criminal, nada é mais importante que a pena. 
É com ela que o Estado exerce sua função preventiva e repressiva. Não ignoro que não extingue e nem faz desaparecer o crime. Os delitos, maximé contra o patrimônio, não cessarão enquanto o dinheiro fôr considerado o fim supremo da vida. Já há muitos anos dizia Ferri que "na nova civilização humana que sucederá à civilização burguêsa, como aquela sucedeu à feudal, as condições de existência serão asseguradas a todo homem, por um trabalho moderado, e, assim, a moralidade se fortificará e se elevará, porque a imoralidade se desenvolve só onde a luta pela existência é muito árdua, devido ao trabalho extenuante, ou muito fácil, pela ociosidade ou parasitismo". Sem autoridade tive também ocasião de dizer: Cada sociedade vive a sua época. Sem romper de todo os élos que a jungem, pela sua condição humana, às que the antecederam, nada justifica e seria mesmo impossível supôr que os princípios e normas que nortearam estas, possam ainda condicionar á existência daquela.

E preciso convencer-se o homem de que se a propriedade não é um roubo, não ẻ também um dirreito ilimitado e absoluto, proclamado pelo liberalismo individualista, cujos excessos e desmandos provocaram a reação coletivista.

Capital e trabalho säo duas forças que se auxiliam e se completam. Se houver prevalência entre êles será certamente ao segundo, pois dêle deriva o capital.

Como falou Leão XIII: "Mais ainda: nesta ordem de coisas, o trabalho tem uma tal fecundidade e uma tal eficácia que se pode afirmar, sem receio de engano, que êle é a fonte única donde promana a riqueza das nações. A equidade manda, pois, que o Estado se preocupe com os trabalhadores e proceda de modo que se todos os bens, que êles proporcionam à sociedade, lhes seja dada uma parte razoável, como habitação e vestuário e que possam viver à custa de menos trabalho e privações".

0 homem, pelo simples fato de nascer, tem direito à vida, que é o bem supremo. Por isso em todos os códigos há um artigo que proibe matar, que pune a supressão violenta da vida humana. Mas há também uma lei moral que interdita matá-lo lentamente pela miséria, pelas privações ou pelo trabalho excessivo e inadequado. 
A igualdade ecor:ômica não exíste; talvez não existirá nunca. Mas a atenuação da desigualdade é possível. 0 Estado, como coordenador das atividades sociais, não pode ser indiferente à solução do problema. Já se passaram os tempos em que a fôrça coercitiva podia sufocar no homem os anceios de felicidade. Incumbe àquele proporcionar ao indivíduo condiȩões de vida, de acôrdo $\mathrm{com}$ suá dignidade humaná.

Usando a linguagem de Hegel, yemo-nos, hoje, entre dois extremos: a tese - o individualismo - - a antítese - o coleti. vismo -; delas há de surgir a sintese que proporcionará não para a geração atual, mas para as pósteras um mundo melhor.

Mas vaticínios de um futuro feliz não nos podem fazer esquecer o problema do presente. $O$ crime existe e é companheiro funesto do homem. Contra êle, nada ainda se tem que não seja a pena. Tem eỉa evoluido, é certo, tornando-se cada vez mais humana. Proclama-se como sua finalidade a intimidação, a reeducação social, a defesa da coletividade e a terapêutica do delinquente. Nessa direção, a humanidade muito avançou nos últimos tempos, tornando sempre mais suportáveis os regimes penitenciários.

Mesmo assim, a pena não perdeu de todo seu caráter de expiação. Não se pode, é verdade, tomar em tôda a amplitude o pensamento de Kant que "o direito penal é aquêle que o representante do poder tem sôbre o indivíduo, com o fim de puní-lo por um crime, mediante a inflição de uma dôr", afastando qualquer investigação acêrca da utilidade própria do castigo. Mas o conceito da retribuição jurídica do pensador germânico não deixa de existir no conteúdo da pena. Ela, importando restrições de direitos e privação maior ou menor da liberdade, é sempre um mal que se impõe ao delinquente pelo mal do crime que praticou. Tanto assim que ainda hoje a generalidade dos códigos a prefixam abstratamente consoante a gravidade do delito: tanto mais grave êste, tanto mais pesada aquela.

Razão, pois, me assiste, quando me oponho à aludida interpretação judiciária, por demais benigna para criminosos de delitos que ferem a fundo o acanhado patrimônio do pobre. Razão, pois, me assiste quando apelo para o M. Público, que, na defesa da sociedade, não aceite, sem acurado exame a exegese apontada. 
Não vai nisso nenhuma postergação dos direitos do réu. Aliás, quanto a mim, desde o início de minha modesta vida de Promotor Público, tenho gravadas na retentiva as palavras de jurista francês: "Deux interêts également puissants, également sacrés veulent être à la fois protegés: l'interêt général de la societé qui veut la juste et la prompte répression des délits; l'interêt des acusés, qui est bien aussi un interêt social et qui exige complète garantie des droits".

Mas os direitos do acusado não podem anular os interêsses sociais confiados à guarda do M. Público. E para que sua defesa se torne cada vez mais eficaz, é de mister que aperfeiçoemos nossa instituição. Mercê de Deus algo já conseguimos. Pertence a passado, que se vai tornando longínquo, aquilo que Rui Barbosa dizia do M. Público: "expressão abstrata e imprópria de elementos esparsos e desagregados, sem corpo orgânico, sem entidade constituida, sem existência pessoal", embora já Pimenta Bueno houvesse assinalado ser "o guarda vigilante e enérgico da ordem pública e repressão aos delitos".

É êle o mais potente propulsor da máquina judiciária, imprimindo-lhe indispensável dinamismo à tarefa vital da distribuição da justiça.

Longa foi a estrada batida das nossas reivindicações e árduas as lutas travadas. Exitos vieram coroar os esforços despendidos. Não nos satisfaremos, porém. Devemos prosseguir na arrancada que colima uma estruturação perfeita da nossa classe em todos os Estados, constituindo organismos harmônicos e, assim, possamos, um dia, no templo da Justiça, sob o pálio de direitos inconcussos, erguer bem alto no pedestal da sua dignidade o M. Público Brasileiro! 